\title{
THE DOCTOR IN MY MIND: HEALTH LITERACY
}

\author{
Hakan Demirci \\ Department of Family Medicine, University of Health Sciences, Bursa Yuksek Ihtisas \\ Training and Research Hospital, Bursa, Turkey
}

\begin{abstract}
Although very popular in developed countries, health literacy in many other countries does not receive the attention it deserves. Most of the physicians I talked to about this issue stated that they heard the term health literacy for the first time. Or, they didn't know much about health literacy. A colleague of mine, for example, realized that it was a significant issue only when his article on health literacy was accepted for publication. Health literacy research can also be difficult to publish. When you do research on this topic, your article submitted to non-specific journals on this subject is often rejected. The European Health Literacy Journal aims to fill the gap in this area.
\end{abstract}

As is well-known, health literacy is examined under three subtitles. These are: utilization of health services, health protection and health promotion. As can be understood from the subheadings, health literacy deals with health in three dimensions. Patients with better health literacy are those who know what to do in an emergency (1-3). To the patients we surveyed we asked, "Do you know what to do in an emergency?" Most patients give themselves full points. But when we asked these patients, "Can you give an example?", they all answered, "I call the emergency service". However, more scientific answers could be expected. In one study, we found that patients who have good health literacy and who read books at a higher rate use emergency services more efficiently. When we saw this result, my colleague said: "Then let's set up a library in the emergency room".

You can clearly see the relationship between health literacy and mathematical thinking skills in the Newest Vital Sign (NVS) Scale (4). This scale is one of the most commonly used measures in health literacy. The European Health Literacy Scale (HLS-EU) is another measure frequently used by researchers. The scale, originally consisting of 47 questions, is a guide both in evaluating the health literacy of the participants and also in determining the issues they themselves feel are lacking. For example, in a study conducted with elderly people, it has been shown that participants have difficulty in making decisions about health issues. It is clear on which subject a participant needs training if she/he has low scores on vaccines or periodic examinations (5).

In conclusion, health literacy is an important detail in our lives. It expresses the ability to understand rights in health and act properly. Health literacy today remains a social issue rather than an academic one. Obviously specific journals on health literacy will strengthen the academic aspect. The European Health Literacy Journal begins its publication life in order to publish your valuable articles on health literacy. 


\section{References}

1. Morris RL, Soh SE, Hill KD et al. Measurement properties of the health literacy questionnaire (HLQ) among older adults who present to the emergency department after a fall: a Rasch analysis. BMC health services research, 2017; 17(1): 1-11.

2. Balakrishnan MP, Herndon JB, Zhang J, Payton T, Shuster J, Carden DL. The association of health literacy with preventable emergency department visits: a cross-sectional study. Academic Emergency Medicine. 2017; 24(9): 1042-1050.

3. Greene JC, Haun JN, French DD, Chambers SL, Roswell RH. Reduced hospitalizations, emergency room visits, and costs associated with a web-based health literacy, alignedincentive intervention: mixed methods study. Journal of medical Internet research. 2019; 21(10): e14772.

4. Ciftci F, Demirci H, Ciftci HN, OCAKOĞLU G. Validation of Turkish Version of Newest Vital Sign Scale to Assess Health Literacy. Bezmialem Science. 2021; 9(2): 219.

5. Bozkurt $H$, Demirci $H$. Health literacy among older persons in Turkey. The Aging Male. 2019; 22(4): 272-277. 